\title{
Incorporating and integrating cognitive event- related potentials in the management of psychiatric disorders
}

This article was published in the following Dove Press journal:

Neuropsychiatric Disease and Treatment

10 January 2014

Number of times this article has been viewed

\author{
Nicola Luigi Bragazzi ${ }^{1,2}$ \\ Giovanni Del Puente ${ }^{2}$ \\ 'School of Public Health, Department \\ of Health Sciences (DISSAL), \\ University of Genoa, Genoa, \\ Italy; ${ }^{2}$ DINOGMI, Department \\ of Neuroscience, Rehabilitation, \\ Ophtalmology, Genetics, Maternal and \\ Child Health, Section of Psychiatry, \\ University of Genoa, Genoa, Italy
}

\section{Dear editor}

Dr Salvatore Campanella has recently advocated the urgent need to incorporate cognitive event-related potentials (ERPs) for a proper diagnosis, treatment, and prognosis of psychiatric disorders, on the basis of four working hypotheses, which are theoretically solid and experimentally supported. ${ }^{1}$

Psycho-pathological diseases are characterized by a cognitive impairment (first argument) and the task of ERP methodology is to investigate these very cognitive alterations (second argument), in a more effective, fast, reliable and comprehensive way than the traditional administration of neuropsychological tests and questionnaires, which are rather time-consuming and difficult to implement in everyday clinical practice. Furthermore, ERP is able to discriminate among similar behaviors (third argument), thus having potential benefits and clinically relevant implications, as it would enable an ERP-based neuropsychological and cognitive treatment (a "directed cognitive retraining procedure") (fourth argument). Moreover, this treatment would be targeted and personalized, since specifically designed and focused on the cognitive deficit of the patient, and ERP would logically and coherently link the three moments of clinical practice: diagnosis, treatment and prognosis. ERP, indeed, does not only provide the approach and the target of the clinical intervention, but makes also possible to monitor its effects. ${ }^{2}$

Interest in ERP, however, is not recent, even though it has been quite erratic throughout the decades, and examples of ERP-like paradigms can be found in Bleuler's clinical observations of schizophrenic patients. ${ }^{3}$ Scholars have progressively enriched the ERP paradigm with phenomenological, clinical, and psychological observations, and some researchers have speculated that ERPs could have a genetic and/or environmental basis and thus could be inherited, meeting with the requirements of the Gottesman and Gould principles ${ }^{4}$ for defining a trait as an endophenotype. ERPs have been proven to be reproducible, with good-to-excellent psychometric properties and are promising biomarkers. ${ }^{5}$ The technical and technological advancements in the field of electroencephalography (EEG) (the transition from scalp EEG to source EEG and quantitative EEG, and the introduction of portable and wearable sensors for real-time monitoring) coupled with powerful computational processing approaches ${ }^{5,6}$ have further revolutionized the usefulness and the applications of ERPs, making more feasible the transition from bench to patient bedside.
Correspondence: Nicola Luigi Bragazzi School of Public Health, Department of Health Sciences (DISSAL),

University of Genoa, Via Antonio

Pastore I, Genoa, Italy

Tel +39010 3537664

Fax +390103537669

Email robertobragazzi@gmail.com 
Moreover, ERP can be integrated with functional magnetic resonance imaging (fMRI), positron emission tomography (PET) and other sophisticated and advanced imaging devices, thus acquiring more clinical significance and relevance. ${ }^{7}$

In conclusion, psychiatric disorders are complex diseases $^{8}$ and complex problems call for complex solutions: an integrated, multidisciplinary team, including all the professional figures who deal with all the different aspects of brain-related disorders - from the psychiatrist to the social worker and occupational therapist; from the psychologist to the neurologist - could cope with the challenges that arise from the necessity to integrate and coordinate the different methods and approaches. This, of course, should be reflected also in designing the university syllabus and residential curricula, putting emphasis on the different souls of the psychiatry (the biological and the psychological strains) and its intrinsic multidisciplinary nature.

\section{Disclosure}

The authors report no conflicts of interest in this communication.

\section{References}

1. Campanella S. Why it is time to develop the use of cognitive event-related potentials in the treatment of psychiatric diseases. Neuropsychiatr Dis Treat. 2013, 9:1835-1845.

2. Zaunmüller L, Lutz W, Strauman TJ. Affective impact and electrocortical correlates of a psychotherapeutic microintervention: an ERP study of cognitive restructuring. Psychother Res. 2013 Nov 28. [Epub ahead of print].

3. Micoulaud Franchi JA, Vion Dury J, Cermolacce M. [Neurophysiological endophenotypes and schizophrenic disorder: emergence and evolution of a clinical concept]. Encephale. 2012;38 Suppl 3:S103-S109. French.

4. Gottesman II, Gould TD. The endophenotype concept in psychiatry: etymology and strategic intentions. Am J Psychiatry. 2003;160(4):636-645.

5. McLoughlin G, Makeig S, Tsuang MT. In search of biomarkers in psychiatry: EEG-based measures of brain function. Am J Med Genet $B$ Neuropsychiatr Genet. 2013 Nov 25. [Epub ahead of print].

6. Gordon E, Cooper N, Rennie C, Hermens D, Williams LM. Integrative neuroscience: the role of a standardized database. Clin EEG Neurosci. 2005;36(2):64-75.

7. Campanella S, Bourguignon M, Peigneux $\mathrm{P}$, et al. BOLD response to deviant face detection informed by $\mathrm{P} 300$ event-related potential parameters: a simultaneous ERP-fMRI study. Neuroimage. 2013;71:92-103.

8. Bragazzi NL. Rethinking psychiatry with OMICS science in the age of personalized P5 medicine: ready for psychiatome? Philos Ethics Humanit Med. 2013;8(1):4.
Neuropsychiatric Disease and Treatment

\section{Publish your work in this journal}

Neuropsychiatric Disease and Treatment is an international, peerreviewed journal of clinical therapeutics and pharmacology focusing on concise rapid reporting of clinical or pre-clinical studies on a range of neuropsychiatric and neurological disorders. This journal is indexed on PubMed Central, the 'PsycINFO' database and CAS.

\section{Dovepress}

The manuscript management system is completely online and includes a very quick and fair peer-review system, which is all easy to use. Visit http://www.dovepress.com/testimonials.php to read real quotes from published authors. 